\title{
ABSTRAK \\ PENGARUH PENGGUNAAN GADGET TERHADAP PERKEMBANGAN PSIKOSOSIALANAK USIA PRASEKOLAH (3- 6 TAHUN) DI TK PGRI KABUPATEN POLEWALI MANDAR TAHUN AJARAN 2017-2018
}

\author{
Masyitah Wahab ${ }^{1}, \operatorname{Irfan}^{2}$, Musdalifah Mahyuddin ${ }^{3}$, Andi Nurfaika ${ }^{4}$
}

Perkembangan teknologi akan gadget saat ini telah mengakibatkan adiksi berlebihan bagi penggunanya, baik itu kepada orang dewasa maupun anak-anak, orang tua memegang kendali penuh untuk menghindarkan anak dari adiksi berlebihan pada gadget, namun para orang tua muda cenderung memberikan gadget kepada anak mereka sedini mungkin dengan alas an kepraktisan, dimana orang tua dapat lebih mudah mengontrol dan mengetahui apa yang dilakukan anak mereka. Penelitian ini bertujuan untuk mengetahui pengaruh gadget terhadap perkembangan psikososial anak usia prasekolah (3-6 tahun) di TK PGRI Kabupaten Polewali Mandar Tahun Ajaran 2017-2018. Metode penelian yang digunakan yaitu deskriptif korelasi, sedangkan bentuk penelitian yang digunakan yaitu cross sectional dengan sampel sebanyak 69 responden. Hasil analisis menggunakan uji chi-square, diketahui nilai $\mathrm{p}=0,000 \leq \alpha 0,05$.Nilai ini menyatakan bahwa ada pengaruh penggunaan gadget terhadap perkembangan psikososial anak usia prasekolah (3-6 tahun) Tahun Ajaran 2017-2018.

Kesimpulan Ada pengaruh penggunaan gadget terhadap perkembangan psikososial anak usia prasekolah (3-6 tahun) di TK PGRI Kabupaten Polewali Mandar.

Kata Kunci :Gadget, perkembangan psikososial, usia prasekolah

\author{
ABSTRACT \\ THE EFFECT OF GADGET USE ON PSYCHOSOCIAL DEVELOPMENT \\ OF CHILDREN AGE (3-6 YEARS) IN TK PGRI DISTRICT \\ POLEWALI MANDAR ACADEMIC YEAR 2017-2018
}

Masyitah Wahab ${ }^{1}, \operatorname{Irfan}^{2}$, Musdalifah Mahyuddin ${ }^{3}$, Andi Nurfaika $^{4}$ 
The technological development of gadgets today has resulted in excessive addiction to its users, both for adults and children, parents have full control to avoid children from excessive addiction to gadgets, but today young parents tend to give gadgets to their children as early as possible for reasons of practicality, where parents can more easily control and know what their child is doing. This study aims to determine the effect of gadgets on the psychosocial development of preschoolers (3-6 years) at the Kindergarten PGRI PolewaliMandar District Academic Year 2017-2018. Methods The type of research used is descriptive correlation, while the form of research used is cross sectional with a sample of 69 respondents. The results of the analysis using chi-square test, it is known that the value of $p=0,000 \leq \alpha 0,05$. This value states that there is an influence of gadget usage on psychosocial development of pre-school age children (3-6 years) 2017-2018 Academic Year.

Conclusion There is an influence of gadget usage on psychosocial development of preschoolers (3-6 years) at the PolewaliMandar Regency PGRI Kindergarten

\section{Keywords: Gadgets, psychosocial development, preschool age}

\section{PENDAHULUAN}

\section{Latar Belakang}

Mengasuh, membesarkan, dan mendidik anak merupakan satu tugas mulia yang tidak lepas dari berbagai halangan dan tantangan.Didalam psikologi perkembangan banyak dibicarakan bahwa dasar kepribadian seseorang terbentuk pada masa anakanak. Proses-proses perkembangan yang terjadi dalam diri seorang anak ditambah dengan apa yang dialami dan diterima selama masa anakanaknya secara sedikit demi sedikit memungkinkan ia tumbuh dan berkembang menjadi menusia dewasa.

Perkembangan psikososial merupakan proses sepanjang hayat, apa yang dipelajari dalam tahuntahun pertama kehidupan akan membentuk perkembangan dimasa yang akan datang. Perkembangan psikososial yang lengkap akan memiliki personality yang baik, memiliki sifat-sifat yang positif seperti percaya pada diri dan orang lain, serta mencapai kesempurnaan ego. (Studi et al., 2012)

Sedangkan anak prasekolah adalah anak-anak yang berada dalam rentang usia 3-6 tahun. Disebut masa prasekolah karena anak mulai mempersiapkan diri memasuki dunia sekolah melalui kelompok bermain. Pada masa ini, anak yang tadinya hanya mendapatkan pendidikan informal dari orang tua ataupun keluarga, akan mulai mengenal 
lingkungan luar rumah dan akan bertemu dengan teman-teman sebayanya. Sehingga pada tahap ini pula anak-anak akan lebih sering bermain, lebih aktif, memiliki tenaga, rasa keingintahuan yang lebih dan semakin berani untuk mencoba hal-hal baru yang sebelumnya tidak ia temui ketika di rumah. (Gunawan, 2017)

Terdapat beberapa masalah perkembangan psikososial (emosional dan sosial) anak usia prasekolah yang sering muncul yaitu ledakan amarah, takut, iri hati ingin memiliki barang milik orang lain, adanya perasaan cemburu, umumnya anak terlihat agak malas dan pasif, jarang berpartisipasi secara aktif serta muncul perbedaan pemahaman antara kepercayaan dan keinginan seorang anak pada saat anak melakukan aktivitas bersama teman sebayanya. Ditambah lagi, semakin berkembangnya zaman tidak bisa dipungkiri bahwa perkembangan teknologi informasi dan komunikasi berlangsung semakin pesat dan penggunaannya telah menjangkau keberbagai lapisan kehidupan masyarakat dari segala bidang, usia dan tingkat pendidikan. (Trinika, 2015)

\section{World Health Organization} (WHO) melaporkan bahwa 5-25\% dari anak-anak usia prasekolah menderita gangguan perkembangan. Berbagai masalah perkembangan anak, seperti keterlambatan motorik, bahasa, dan perilaku sosial dalam beberapa tahun terakhir ini semakin meningkat.Angka kejadian masalah perkembangan pada anak di Indonesia antara 13-18\%. Sekitar 9,5\% sampai $14,2 \%$ anak prasekolah memiliki masalah sosial emosional yang berdampak negatif terhadap perkembangan dan kesiapan sekolahnya. Sedangkan penelitian lain menunjukkan bahwa sekitar 8 sampai 9\% anak prasekolah mengalami masalah psikososial khususnya masalah social emosional seperti kecemasan, susah beradaptasi, susah bersosialisasi, susah berpisah dari orang tua, anak sulit diatur, dan perilaku agresif merupakan masalah yang paling sering muncul pada anak usia prasekolah. Profil masalah kesehatan perkembangan anak pada tahun 2010 dilaporkan bahwa dari jumlah anak sebanyak 3.634.505 jiwa, ditemukan $54,03 \%$ anak dideteksi memiliki kemampuan sosialisasi dan kemandirian yang baik, akan tetapi cakupan tersebut masih di bawah target yakni 90\%. Bahwa anak berhubungan dengan teman sebaya $10 \%$ dari waktunya setiap hari pada usia 2 tahun, 20\% pada usia 4 tahun dan lebih dari $40 \%$ pada usia antara 7-11 tahun. Hubungan dengan teman sebaya sangat kuat mempengaruhi perkembangan seorang anak.(Gunawan, 2017) Data dari Kementrian Kesehatan Republik Indonesia (KEMENKES) 2013,jumlah penduduk di Indonesia sebesar 
248.422.956 jiwa, dimana jumlah anak usia sekolah 29.063.346 jiwa. Berdasarkan buku data pendidikan anak usia dini (PAUNDIN), jumlah anak usia sekolah di Provinsi riau tahun 2013 dengan umur 6-12 tahun sebanyak 728.282 anak dengan total penduduk 6.003.300. Berdasarkan data masalah anak usia sekolah menurut Riset Kesehatan Dasar (Riskesdas) tahun 2013, umur $\geq 10$ tahun memiliki kebiasaan merokok setiap hari 0,5 persen, yang mempunyai kebiasaan mengunyah tembakau setiap hari sebanyak 2 persen. Banyaknya penduduk pada tahap perkembangan anak usiasekolah, menjadisalah satu penyebab tingginya masalah kenakalan pada usia sekolah. (Irmilia \& Dkk, 2015)

Salah satu faktor atau stimulus yang dapat mempengaruhi perkembangan anak yaitu kebiasaan anak dalam bermain gadget.Pada jaman yang serba modern, kehidupan menjadi serba praktis, efektif dan efisien.Oleh sebab itulah diciptakan alat-alat yang sekiranya membantu kelancaran dan meringankan beban pekerjaan manusia, salah satunya adalah gadget.Gadget memberikan banyak manfaat, dari mulai sebagai alat komunikasi, media informasi, sampai sebagai media hiburan.Banyaknya manfaat yang diberikan gadget membuat kita merasa nyaman atau bahagia.(Tiawan/Agus, 2015)
Gadget merupakan perkembangan teknologi yang saat ini sangat berkembang dalam masyarakat, mayoritas masyarakat telah dapat menerima gadget sebagai pendukung gaya hidup mereka. Di negara kita Indonesia sendiri, keberadaan gadget juga telah sangat lekat dengan kehidupan masyarakat. Di sekitar kitapun, jika kita perhatikan akan terdapat suatu fenomena menarik, di berbagai tempat akan jamak ditemui orangorang yang asik dengan gadget masing-masing, seakan-akan gadget telah menjadi suatu fungsi yang signifikan dalam kehidupan sosial masyarakat. Perkembangan teknologi akan gadget saat ini telah mengakibatkan adiksi berlebihan bagi penggunanya, baik itu kepada orang dewasa maupun anak-anak, orang tua memegang kendali penuh untuk menghindarkan anak dari adiksi berlebihan pada gadget, namun dewasa ini, para orang tua muda cenderung memberikan gadget kepada anak mereka sedini mungkin dengan alasan kepraktisan, dimana orang tua dapat lebih mudah mengontrol dan mengetahui apa yang dilakukan anak mereka.

Kecanduan gadget pada anak memiliki banyak akibat negatif, seperti contohnya anak menjadi jarang bergerak dan hanya bermain dengan gadgetnya sehingga banyak anak menjadi obesitas, radiasi gadgetyang terus menerus juga tidak baik untuk anak yang sedang 
mengalami tumbuh kembang, bahkan lebih parahnya lagi, banyak orang tua muda yang berpikir bahwa dengan adanya gadget, anak mereka telah memiliki "digital babysitter" yang dapat membuat anak-anak mereka lebih tenang. Memang dengan keadaan dan situasi serba modernseperti sekarang ini tidak bijak rasanya jika melarang anak untuk tidak menggunakan gadget sama sekali, karena dengan adanya gadget, memang banyak kemudahan yang didapatkan, namun dibalik kemudahan itu, juga terdapat hal-hal yang kurang baik yang ditimbulkan oleh gadget itu sendiri, oleh karenanya orang tua harus dapat lebih bijak dan disiplin lagi dalam mengontrol penggunaan gadgetuntuk anak-anaknya. (Viona, 2015)

Dahulu, handphonedan PC tablet hanya digunakan dikalangan usia dewasa untuk berkomunikasi dan urusan pekerjaan saja dan orangorang yang memiliki pendapatan tinggi karena harga gadget yang mahal. Namun sekarang bukan hanya dikalangan dewasa tetapi usia remaja dan usia dini seperti anak usia prasekolah atau anak TK pun sudah menggunakan gadgetkarena faktor orang tua yang sibuk bekerja dan harga gadget yang semakin murah akibat persaingan dipasaran. Sedangkan, aplikasi-aplikasi yang terdapat pada PC tablet atau smartphonetersebut bukan hanya aplikasi tentang pembelajaran mengenal huruf ataugambar, tetapi terdapat aplikasi hiburan, seperti sosial media, video, gambar bahkan video game. Pada kenyataannya, anak-anak akan lebih sering menggunakan gadgetnya untuk bermain game daripada untuk belajar ataupun bemain di luar rumah dengan teman-teman seusianya. (Trinika, 2015)

Berdasarkan hasil studi pendahuluan yang telah dilakukan oleh calon peneliti pada tanggal 05 Januari 2018 di TK PGRI Kabupaten Polewali Mandar, sekitar 60\% anak usia prasekolah (3-6 tahun) dapat menggunakan gadget. Dari hasil wawancara dengan salah satu guru di TK PGRI Kabupaten Polewali Mandar beliau mengatakan bahwa anak-anak tersebut pandai menggunakan gadget, seperti mengetahui cara menggunakan aplikasi game, aplikasi media sosial, menggunakan kamera, dan lain sebagainya. Calon peneliti juga melakukan wawancara terhadap beberapa anak murid yang diambil secara acak dari beberapa kelompok belajar yang ada di TK PGRI Kabupaten Polewali Mandar. Dari beberapa anak murid tersebut, mengaku mengetahui beberapa cara penggunaan dari gadget, bahkan ada pula yang memiliki gadget sendiri yang di berikan oleh orang tuanya tanpa mengetahui dampak atau pengaruh gadget terhadap anaknya. Sedangkan pada saat calon peneliti melakukan wawancara terhadap anak murid tersebut, anak-anak seperti 
kurang memperhatikan ketika diminta keterangan mengenai gadget karena begitu senang bermain dengan teman-temannya, anak-anak tersebut bermain bersama meskipun dari beberapa yang diamati oleh calon peneliti ada yang terkadang bertengkar karena masalah kecil tetapi tidak membutuhkan waktu yang lama untuk berteman dan

\section{METODE PENELITIAN}

\section{Desain Penelitian}

Desain penelitian adalah jenis penelitian yang akan digunakan untuk mencapai tujuan penelitian. (Arikunto, 2010)

Desain penelitian atau rancangan penelitian yang digunakan adalah deskriptif korelasi. Metode deskriptif korelasi yaitu metode penelitian yang mengkaji hubungan antara dua variable atau lebih dengan tujuan mengungkapkan hubungan korelatif antar variabel. Adapun bentuk bermain bersama kembali.Oleh karena itu, peneliti tertarik untuk melakukan penelitian dengan mengangkat judul "Pengaruh Penggunaan Gadget Terhadap Perkembangan Psikososial Anak Usia Prasekolah (3-6 Tahun) Di TK PGRI Kabupaten Polewali Mandar." penelitian yang digunakan yaitu cross sectional, dalam penelitian seksional silang, variabel sebab atau risiko dan akibat yang terjadi pada objek penelitian diukur dan dikumpulkan secara simultan, sesaat atau satu kali saja dalam satu kali waktu yang bersamaan, tidak ada follow up. Pada penelitian ini, peneliti ingin mengetahui antara pengaruh penggunaan gadget terhadap perkembangan psikososial anak usia prasekolah di TK PGRI Kabupaten Polewali Mandar.

\title{
Hasil Penelitian
}

Dari hasil penelitian yang dilakukan di TK PGRI Kabupaten Polewali Mandar yaitu sebagai berikut :

\section{Karakteristik Responden}

Umur

Dari hasil penelitian, distribusi frekuensi berdasarkan umur responden dapat dilihat pada tabel di bawah ini :

\author{
Tabel 4.1
}

Gambaran Distribusi Perkembangan Psikososial Berdasarkan Umur

\section{Umur Responden}

Percent 


\begin{tabular}{ccc}
3 tahun & 8 & $11,6 \%$ \\
\hline 4 tahun & 43 & $62,3 \%$ \\
\hline 5 tahun & 17 & $24,6 \%$ \\
\hline 6 tahun & 1 & $1,4 \%$ \\
\hline Total & 69 & $100,0 \%$
\end{tabular}

Sumber :Data Primer, 2018

$\begin{array}{lrrrr} & \text { Berdasarkan tabel } 4.1 & & \text { berumur } & \text { 4tahun( }(62,3 \%), 17 \\ \text { diatas } & \text { menunjukkan bahwa } & \text { responden } & \text { berumur } \\ \text { dari } 69 \quad \text { responden, } 8 & \text { benun(24,6\%), } & \text { dan } 1 \\ \text { responden } & \text { berumur } & \text { responden } & \text { berumur } \\ \text { 3tahun(11,6\%), } 43 \text { responden } & \text { 6tahun }(1,4 \%) . & \end{array}$

Jenis Kelamin

Dari hasil penelitian, distribusi frekuensi berdasarkan jenis kelamin responden dapat dilihat pada tabel di bawah ini:

Tabel 4.2

Gambaran Distribusi Perkembangan

PsikososialBerdasarkan

Jenis Kelamin

\begin{tabular}{ccc}
\hline Jenis Kelamin & N & Percent \\
\hline Laki-laki & 35 & 50,7 \\
\hline Perempuan & 34 & 49,3 \\
\hline Total & 69 & 100,0
\end{tabular}

Sumber :Data Primer, 2018

\begin{tabular}{lllll}
\multicolumn{2}{c}{ Berdasarkan tabel 4.2 diatas } & kelamin laki-laki(50,7\%) & dan 34 \\
menunjukkan bahwa dari 69 & responden berjenis & kelamin \\
responden, 35 & responden berjenis & perempuan $(49,3 \%)$. &
\end{tabular}

\section{Analisa Univariat}

Distribusi Responden menurut Durasi Penggunaan Gadget 
Distribusi responden menurut durasi penggunaan gadget dapat dilihat pada tabel berikut :

Tabel 4.3

Distribusi Responden Berdasarkan

Durasi Penggunaan Gadget

\begin{tabular}{ccc}
\hline $\begin{array}{c}\text { Durasi } \\
\text { Penggunaan } \\
\text { Gadget }\end{array}$ & N & Percent \\
\hline Rendah & 35 & 50,7 \\
\hline Tinggi & 34 & 49,3 \\
\hline Total & 69 & 100,0 \\
Sumber :Data Primer, 2018 &
\end{tabular}

Berdasarkan tabel 4.3 diatas $\operatorname{rendah}(50,7 \%)$ dan 34 responden menunjukkan bahwa dari 69 responden, 35 penggunaan gadgetnya tinggi $(49,3)$.

responden penggunaan gadgetnya

Distribusi Responden menurut Psikososial Anak

Distribusi responden menurut durasi penggunaan gadget dapat dilihat pada tabel berikut :

Tabel 4.4

Distribusi Responden Berdasarkan

Psikososial Anak

\begin{tabular}{ccc}
\hline $\begin{array}{c}\text { Psikososial } \\
\text { Anak }\end{array}$ & N & Percent \\
\hline Baik & 35 & 50,7 \\
\hline Buruk & 34 & 49,3 \\
\hline Total & 69 & 100,0
\end{tabular}

Sumber :Data Primer, 2018

Berdasarkan tabel diatas, baik(50,7\%) dan 34 responden menunjukkan bahwa dari 69 responden, 35 perkembangan psikososialnya responden perkembangan psikososialnya buruk(49,3\%).

\section{Analisa Bivariat}

Pada penelitian ini di gunakan Uji Chi-Squareuntuk mengetahui pengaruh Penggunaan Gadget terhadap Perkembangan Psikososial Anak Usia Prasekolah (3-6 tahun) di TK PGRI Kabupaten Polewali Mandar. 
Tabel 4.5

Pengaruh Penggunaan Gadget terhadap Perkembangan Psikososial Anak Usia Prasekolah (3-6 tahun) di TK PGRI Kabupaten Polewali Mandar

\begin{tabular}{ccccc} 
Durasi & \multicolumn{2}{c}{ Psikososial Anak } & Total & $P$ \\
\cline { 2 - 3 } $\begin{array}{c}\text { Penggunaan } \\
\text { Gadget }\end{array}$ & Baik & Buruk & & \\
\hline Rendah & 35 & 0 & 35 & \multirow{2}{*}{0.000} \\
\hline$\%$ & 50,7 & 0 & $50,7 \%$ \\
\hline Tinggi & 0 & 34 & 34 \\
\hline$\%$ & 0 & 49,3 & $49,3 \%$ \\
\hline Total & 35 & 34 & 69 \\
\hline$\%$ & 50,7 & 49,3 & $100 \%$ &
\end{tabular}

\section{Sumber data sekunder 2018}

Berdasarkan tabel 4.5 diketahui responden dengan durasi penggunaan gadget rendah sebanyak $35 \quad(50,7 \%)$, perkembangan psikososial anak yang baik berjumlah $35(50,7 \%)$ dan perkembangan psikososial anak buruk berjumlah 0 (0\%).Sedangkan responden dengan durasi penggunaan gadget yang tinggi sebanyak 34 (49,3\%),perkembangan psikososial yang baik sebanyak $0 \quad(0 \%)$ dan psikososial anak buruk berjumlah $34(49,3 \%)$.

Hasil analisis menggunakan uji chi-square diketahui nilai $p=0,000 \leq \alpha 0,05$ yang berarti ada pengaruh secara signifikan antara kedua variabel.

\section{Pembahasan}

Gadget merupakan perkembangan teknologi yang saat ini sangat berkembang dalam masyarakat, mayoritas masyarakat telah dapat menerima gadget sebagai pendukung gaya hidup mereka. Perkembangan teknologi akan gadget saat ini telah mengakibatkan adiksi berlebihan bagi penggunanya, baik itu kepada orang dewasa maupun anak-anak, orang tua memegang kendali penuh untuk menghindarkan anak dari adiksi berlebihan pada gadget, namun dewasa ini, para orang tua muda cenderung memberikan gadget kepada anak mereka sedini mungkin dengan alasan kepraktisan, dimana orang tua dapat lebih mudah mengontrol dan mengetahui apa yang dilakukan anak mereka.

Kecanduan gadget pada anak memiliki banyak akibat negatif, seperti contohnya, anak menjadi jarang bergerak dan hanya bermain dengan gadgetnya sehingga banyak 
anak menjadi obesitas, radiasi gadgetyang terus menerus juga tidak baik untuk anak yang sedang mengalami tumbuh kembang, bahkan lebih parahnya lagi, banyak orang tua muda yang berpikir bahwa dengan adanya gadget, anak mereka telah memiliki "digital babysitter" yang dapat membuat anak-anak mereka lebih tenang. Pada kenyataannya, anak-anak akan lebih sering menggunakan gadgetnya untuk bermain game daripada untuk belajar ataupun bemain di luar rumah dengan teman-teman seusianya. (Trinika, 2015)

Hasil analisis menggunakan uji chi-square diketahui nilai $\mathrm{p}=0,000 \leq$ a 0,05 sehingga dapat disimpulkan bahwa ada pengaruh penggunaan gadget terhadap perkembangan psikososial anak usia prasekolah (3-6 tahun) di TK PGRI Kabupaten Polewali Mandar.

Kemudian, hasil analisis peneliti pada penelitian ini didapatkan bahwa ada pengaruh penggunaan gadget terhadap perkembangan psikososial anak usia prasekolah (3-6 tahun) di TK PGRI Kabupaten Polewali Mandar tahun Ajaran 2017-2018. Hampir seluruh anak menggunakan gadget di dalam kehidupan sehari-hari mereka, penggunaan gadget tersebut pada umumnya tidak hanya digunakan untuk mereka belajar namun untuk bermain pula. Pada saat menggunakan gadget, waktu yang mereka perlukan untuk bermain game lebih banyak dibandingkan untuk mereka belajar apalagi pada saat mereka tidak didampingi oleh orang tua. Justru, kadangkala orang tua sengaja memberikan gadget kepada anak mereka agar anak tidak bermain diluar rumah dan bahkan tidak mengganggu aktivitas orang tua pada saat dirumah.

Tentu saja hal ini akan menghambat proses sosialisasi anak, karena anak hanya akan asik dengan gadgetnya dan lama kelamaan anak dapat merasa bergantung pada gadget tersebut. Tetapi, berbeda halnya saat seorang anak menggunakan gadget dengan pengawasan orang tua dan adanya pembagian waktu antara penggunaan gadget dengan waktu sosialisasi anak dengan orang lain dilingkungan sekitarnya maka perkembangan psikososial anak akan berkembang dengan baik. Ditambah lagi, jika orangtua lebih banyak menyediakan aplikasiyang bersifat edukasi dan sesuai dengan kemampuan di usia anak tersebut dibandingkan aplikasi game yang kurang bermanfaat untuk anak. Sedangkan berbeda jika orang tua yang kurang memperhatikan aplikasi yang terdapat pada gadget anaknya dan membiarkan anak bermain apapun yang disukai tanpa memilih-milih aplikasi yang mengedukasi maupun tidak. Kemudian, ketika paparan penggunaan gadget pada anak tinggi dan tanpa adanya kontrol ataupun pengawasan dari orang tua, akan 
berdampak buruk juga pada perkembangan psikososial anak, hal ini akan mengakibatkan keterlambatan berfikir pada anak dan anak menjadi susah untuk di atur.

Sejalan dengan penelitian yang dilakukan olehAdevia Maulidya Chikmah(2016) tentang Pengaruh Durasi Penggunaan Gadget Terhadap Masalah Mental Emosional Anak Pra Sekolah, hasil penelitian ini menunjukkan bahwauji korelasi Mann Whitney diperoleh nilai $\alpha$ hitung 0,002 , ini artinya bahwa $\alpha$ hitung lebih kecil dari $\alpha$ tabel $(0,002$ $<0,005)$ yang berarti Ho ditolak dan Ha diterima artinya ada pengaruh antara durasi penggunaan gadget dengan Masalah Mental Emosional pada anak pra sekolah di TK Negeri Pembina Kota Tegal.

Penelitian dini dilakukan oleh Putri Hana Pebriana (2017)tentang Analisis Penggunaan Gadget

\section{PENUTUP}

\section{KESIMPULAN DAN SARAN}

\section{Kesimpulan}

Berdasarkan hasil penelitian
dan pembahasan yang telah
dilakukan terhadap 69 responden
tentang Pengaruh Penggunaan
Gadget Terhadap Perkembangan
Psikososial Anak Usia Prasekolah
(3-6 Tahun) di Kabupaten Polewali
Mandar. Maka dapat disimpulkan
bahwa:

terhadap Kemampuan Interaksi Sosial pada Anak Usia Dini, hasil penelitian ini yaitu penggunaan gadget kebanyakan anak lebih menggunakannya untuk bermain. Dari hal kecil tersebut, anak yang awalnya senang bermain dengan temannya dapat berubah dengan terbiasanya diberikan gadget sebagai pengganti teman bermain.

Dengan demikian hasil penelitian ini dapat disimpulkan bahwa adanya pengaruh pada penggunaan gadget terhadap perkembangan psikososial anak usia prasekolah (3-6 tahun) di TK PGRI Kabupaten Polewali Mandar. Semoga dengan adanya penelitian ini dapat membantu kita dalam lebih mengawasi anak-anak dalam menggunakan gadget agar tidak terganggu pada perkembangan psikososial anak.

Karakteristik responden tingkat umur dapat dilihat dariumur 3 tahun yaitu sebanyak 8 responden atau $(11,6 \%)$, dilihat dari umur 4 tahun yaitu sebanyak 43 responden atau $(62,3 \%)$, dilihat dari umur 5 tahun yaitu sebanyak 17 responden atau $(24,6 \%)$, dan dilihat dari umur 6 tahun yaitu sebanyak 1 responden atau $(1,4 \%)$. Sedangkan Karakteristik responden tingkat jenis kelamin dapat dilihat dari anak laki-laki yaitu sebanyak 35 responden atau $(50,7 \%)$, dan dilihat dari anak perempuan 
yaitu sebanyak 34 responden atau $(49,3 \%)$.

Durasi penggunaan gadget rendah sebanyak 35respondenatau $(50,7 \%)$, perkembangan psikososial anak yang baik berjumlah 35respondenatau $(50,7 \%)$, dan perkembangan psikososial anak buruk berjumlah 0 respondenatau $(0 \%)$. Sedangkan responden dengan durasi penggunaan gadget yang tinggi sebanyak 34 respondenatau $(49,3 \%)$,

perkembangan psikososial yang baik sebanyak 0 respondenatau( $(0 \%)$ dan psikososial anak buruk berjumlah 34 respondenatau $(49,3 \%)$.

Ada pengaruh antara penggunaan gadget terhadap perkembangan psikososial anak usia prasekolah (3-6 tahun). Hasil ini sesuai dengan ujichi-square dimana nilai $p=0,000 \leq \alpha 0,05$.

\section{Saran}

Berdasarkan hasil penelitian dan analisa data mengenai Pengaruh Penggunaan Gadget Terhadap Perkembangan Psikososial Anak Usia Pra sekolah (3-6 Tahun) di Polewali Mandar penulis menyarankan, :

\section{Untuk Sekolah TK PGRI}

\begin{tabular}{lr}
\multicolumn{1}{c}{ Bagi pihak } & sekolah \\
sebaiknya & terus \\
memperhatikan & dan \\
mengidentifikasi & \\
perkembangan psikososial \\
anak sertaperubahan yang \\
terjadi pada perkembangan
\end{tabular}

psikososial anak ketika anak berada dilingkungan pengawasan guru, sehingga guru dapat memberikan pelajaran dalam bentuk kegiatan social pada seluruh murid untuk perkembangan psikososial anak usia prasekolah (3-6 tahun) di TK PGRI Kabupaten Polewali Mandar.

\section{Untuk Istitusi Pendidikan}

Bagi calon perawat khususnya keperawatan anak dan komunitas diharapkan dalam penerapan asuhan keperawatan anak dapat memberikan penyuluhan ataupun sosialisasi kepada masyarakat tentang pengaruh gadget terhadap perkembangan psikososial anak terutama usia prasekolah (3-6 tahun). Perawat dapat membantu anak dan keluarganya melalui peran perawat salah satunya sebagai konselor atau pembimbing, dimana perawat dapat saling bertukarpikiran dan pendapat dengan orang tua anak tentang masalah anak dan keluarganya, serta membantu mencari titik permasalahannya.

\section{Untuk Peneliti}

Semoga penelitian ini memberikan manfat bagi saya sebagai calon perawat. 


\section{DAFTAR PUSTAKA}

- A.A., H. (2007). Riset Keperawatan dan tekhnik penulisan ilmiah, Salemba Medika.

- Adi, Rian Pamungkas, D. (2016). Statistik Untuk Perawat dan Kesehatan Dilengkapi

- Ameliola, S., \& Nugraha, H. D. (2013). Perkembangan Media Informasi dan Teknologi Terhadap Anak Dalam Era Globalisasi, 4. Retrieved from www.academia.edu/downloa d/34462625/2013-02-29.pdf

- Dengan Tutorial SPSS dan Interpretasi Data. (A. Maftuhin, Ed.). Jakarta: CV. Trans Info Media.

- Gunarsa, S. D. (2010). Dasar dan teori perkembangan anak. (1982 BPK Gunung Mulia, Ed.). Retrieved from https://books.google.co.id/bo oks?id=xQsxmVNNU5gC\& $\underline{\mathrm{dq}=\text { perkembangan }+ \text { psikososi }}$ $\underline{\text { al }+ \text { anak } \& \text { hl }=\mathrm{id} \& \text { source }=\mathrm{gbs}}$ _navlinks_s

- Gunawan, M. A. A. (2017). Hubungan Durasi Penggunaan Gadget Terhadap Irmilia, E., \& Dkk. (2015). No Title, 2. Retrieved from https://media.neliti.com/med ia/publications/187559-IDnone.pdf
- IR. JAROT WIJANARKO, M. P., \& Ir. Esther Setiawati, M. P. (2016). Ayah Ibu Baik. (H. H. Kids, Ed.). Retrieved from

https://books.google.co.id/bo oks?id=RGPADQAAQBAJ $\& d q=$ Elizabeth + TS.+3+tand a+anak+adiksi+gadget $+\% 5 \mathrm{~B}$ internet\%5D.+Jakarta:+Kom pas.com\%3B+2015+\%5B\&h $\mathrm{l}=\mathrm{id} \&$ source $=\mathrm{gbs} \_n a v l i n k s \_s$

- Iswidharmanjaya, D., \& Agency, B. (2014). Bila Si Kecil Bermain Gadget: Panduan bagi orang tua untuk memahami factorfaktor penyebab anak kecanduan gadget. (Bisakimia, Ed.). Retrieved from

https://books.google.co.id/bo oks?id=_t_uBQAAQBAJ\&d $\mathrm{q}=$ Pengaruh+Gadget+Terhad ap + Anak \&hl $=\mathrm{id} \&$ source $=\mathrm{gb}$ s_navlinks_s

- Komputindo, E. M. (2005). Keberhasilan Anak ditangan Orang Tua. Retrieved from https://books.google.co.id/bo oks?id=7YCTY8dvJUgC\&d $\mathrm{q}=$ perkembangan+psikososia l+anak+adalah\&hl=id\&sourc e=gbs_navlinks_s

- Patmonodewo, S. (2005). Pendidikan Anak Usia PraSekolah, 85. Retrieved from S Patmonodewo - 2000 - library.walisongo.ac.id

- Perkembangan Anak 
Prasekolah di TK PGRI 33

Sumurboto, Banyumanik.

- Rachbini, D. J., \& Adi, R. (2004). Ekonomi politik: kebijakan dan strategi pembangunan. (Y. O. Indonesia, Ed.). Retrieved from

https://books.google.co.id/bo oks?id=fJPHeIIq2uwC\&dq= kerangka+teori+adalah\&hl=i $\mathrm{d} \&$ source $=\mathrm{gbs} \_$navlinks_s

- Sappaile, B. I. (2007). KONSEP INSTRUMEN PENELITIAN PENDIDIKAN,

- Studi, P., Keperawatan, I., Kedokteran, F., Ilmu, D. A. N., Syarif, U. I. N., \& Jakarta, H. (2012). Anak
Usia 3-6 Tahun Di Panti Sosial Asuhan.

- Trinika, Y. (2015). Pengaruh Penggunaan Gadget Terhadap Perkembangan Psikososial Anak Usia Prasekolah [3- 6 Tahun] Di TK Swasta Kristen Immanuel Tahun Ajaran 2014-2015, 11.

- Viona, V. (2015). AcroRd32. Perancangan Iklan Layanan Masyarakat Penggunaan Gadget Bijaksana Pada Anak Usia 3-5 Tahun Di Surabaya. Retrieved from publication.petra.ac.id/index .php/dkv/article/viewFile/32 $35 / 2924$ 